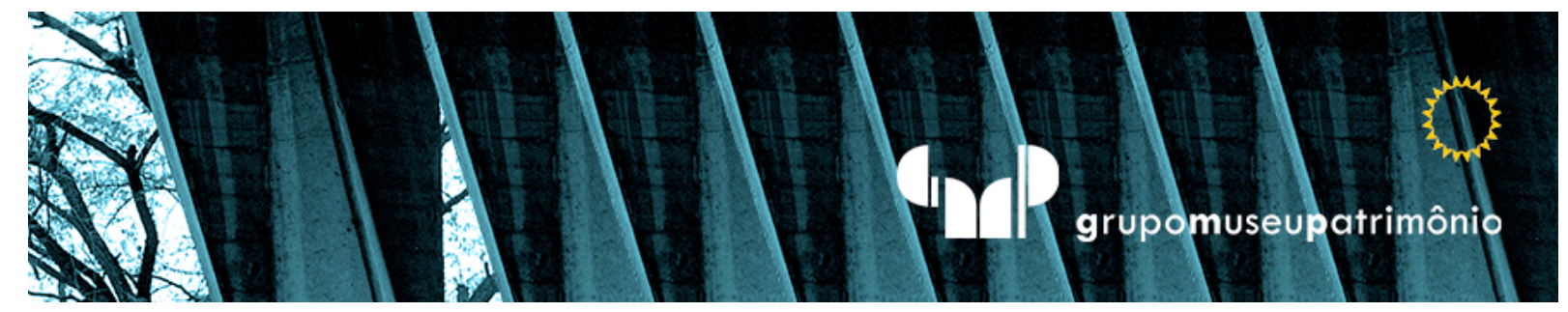

\title{
Poética da presença nos filmes de luz sólida de Anthony McCall'
}

La poética de presencia en películas de luz sólida de Anthony McCall

\section{Poetics of presence in Anthony McCall solid light films}

Fernanda Albuquerque de Almeida

Universidade de São Paulo, São Paulo, Brasil. frnndeaa@gmail.com

\footnotetext{
${ }^{1}$ Este artigo é parte dos resultados da tese Imagens de tempo nas poéticas tecnológicas de Harun Farocki, Bill Viola e Anthony McCall (2019).
} 


\section{Resumo}

Através da análise interpretativa de obras selecionadas e de considerações de Walter Benjamin, Hal Foster e Oliver Grau, este artigo busca investigar o tipo de recepção que os "filmes de luz sólida", de Anthony McCall (1946), suscitam. O objetivo é caracterizar uma poética da presença, que resista a um modo de fruição vinculado ao excesso de estímulos e velocidade, comum na dita sociedade das imagens.

Palavras-Chave: Anthony McCall. Filmes de luz sólida. Walter Benjamin. Hal Foster. Oliver Grau.

\section{Resumen}

Mediante un análisis interpretativo de obras seleccionadas y consideraciones de Walter Benjamin, Hal Foster y Oliver Grau, este artículo busca investigar el tipo de recepción que suscitan las "películas de luz sólida" de Anthony McCall (1946). El objetivo es caracterizar una poética de presencia que resista un modo de disfrute vinculado al exceso de estímulos y velocidad, común en dicha sociedad de imágenes.

Palabras-Clave: Anthony McCall. Películas de luz sólida. Walter Benjamin. Hal Foster. Oliver Grau.

\section{Abstract}

Through an interpretative analysis of selected artworks and considerations of Walter Benjamin, Hal Foster and Oliver Grau, this article seeks to investigate the type of reception that "solid light films", by Anthony McCall (1946), arouse. The goal is to characterize a poetics of presence that resists a mode of enjoyment linked to the excess of stimuli and speed, common in the society of images.

Keywords: Anthony McCall. Solid light films. Walter Benjamin. Hal Foster. Oliver Grau. 


\section{INTRODUÇÃO}

$\mathbf{L}$ ine Describing a Cone (1973) (Figura 1) é uma instalação de Anthony McCall (1946) composta por uma projeção horizontal (em película de 16 $\mathrm{mm}$ ) de uma linha que completa um círculo ao longo de 30 minutos. Quando o círculo é completo, a forma de um cone aparece na junção da projeção com a parede. O espectador pode andar no espaço da instalação, buscando diferentes posicionamentos diante da luz.

Essa é a primeira obra que compõe um amplo grupo conhecido como "filmes de luz sólida" (solid light films). Esse termo se refere à imbricação do cinema e da escultura, ainda inusitada na época em que os primeiros filmes da série foram realizados. Segundo o artista, “o termo 'luz sólida' simplesmente identifica o paradoxo em que os planos de luz parecem ter solidez". E acrescenta: "Mesmo depois que as mãos confirmam que essa impressão é uma ilusão, a mente continua a tratar os planos com certo respeito, como se fossem paredes." Em síntese, "luz sólida" seria uma abreviação de "planos de luz ocupando espaço escultórico" (McCALL apud HOBBS, 2017, p. 15). Esses filmes operam uma expansão da imagem da tela para o espaço, de modo que a 
habitual hierarquia da imagem em relação ao projetor no cinema é quebrada. As figuras não são mais importantes do que a forma de luz que se desenha entre o projetor e a superfície na qual as imagens são projetadas. As obras são constituídas, igualmente, por projetor, luz, imagem e o espaço formado por esses elementos. A conscientização desses componentes também faz parte da proposta. O projetor e a luz por ele difundida, ambos usualmente despercebidos, passam a fazer parte do espaço da obra e do campo de visão do espectador. ${ }^{2}$

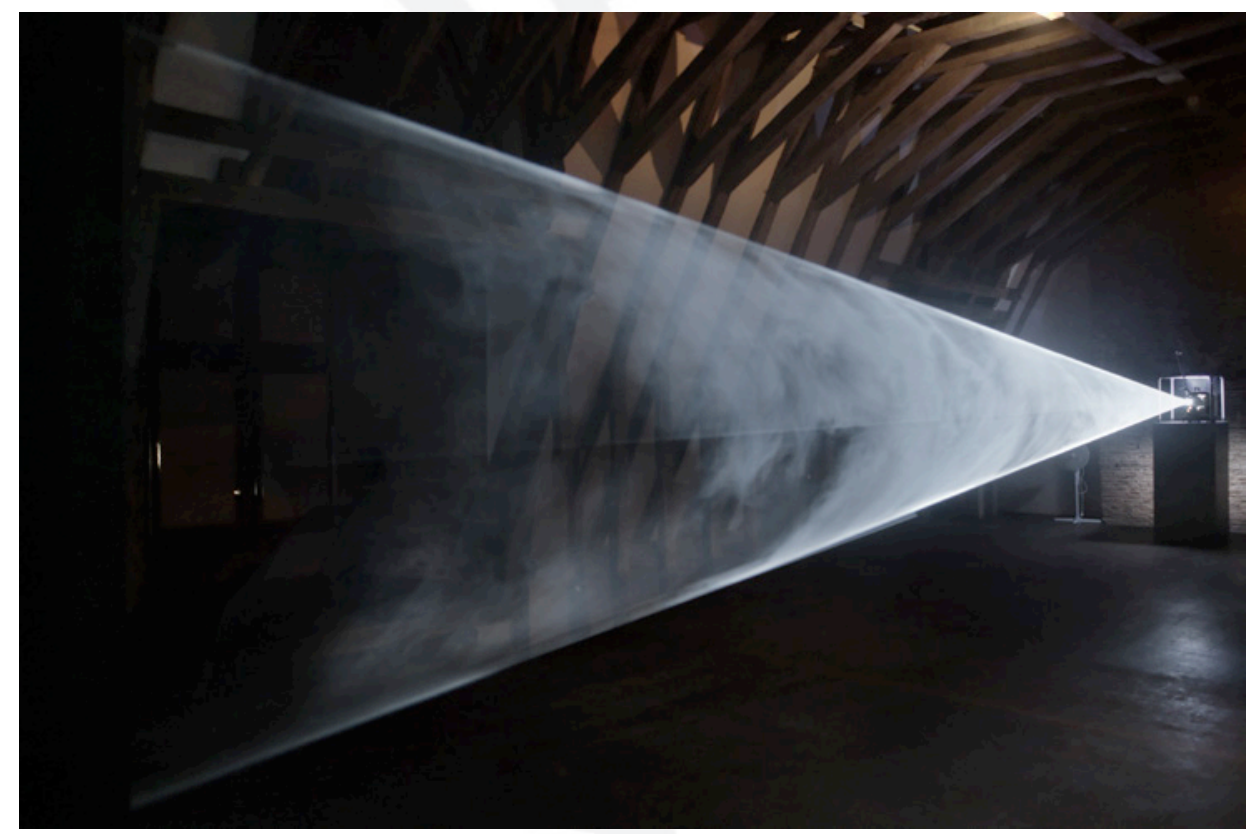

Figura 1. Anthony McCall, Line Describing a Cone (1973), durante o vigésimo quarto minuto. Visão da instalação no Musee de Rochechouart (2007). Fotografia de Freddy Le Saux. Cortesia Sean Kelly Gallery, Nova York, Galerie Thomas Zander, Colônia, Galerie Martine Aboucaya, Paris.

Fonte: Anthony McCall.

\footnotetext{
${ }^{2} \mathrm{O}$ destaque aos elementos constitutivos do cinema, tais como projetor, projeção e variações de luz, consistia a principal proposta dos cineastas agrupados sob a rubrica "cinema estrutural". McCall teve contato com os movimentos de cinema estrutural que ocorreram na Inglaterra e nos Estados Unidos nos anos 1970. Acerca de sua relação com esses movimentos, conferir: McCALL, Anthony. Line Describing a Cone and Related Films. In: October, v. 103. The MIT Press, 2003.
} 
A série dos filmes de luz sólida possui obras realizadas durante a década de 1970 e após os anos 2000. O curioso intervalo de tempo deve-se ao envolvimento do artista em atividades de design (sua área de formação) e à realização de algumas obras conceituais e políticas (HOBBS, 2017, p. 12). O retorno de sua produção se deve especialmente à inclusão de Line Describing a Cone na mostra "Light: The Projected Image in American Art 1964-1977" (2001), a convite da curadora Chrissie Isles no Whitney Museum of Art.

Um dos filmes dos anos 2000 é Meeting You Halfway (2009) (Figura 2). Constituído por projetores digitais e máquina de fumaça, ele prossegue com a proposta de Line Describing a Cone, no qual o ambiente da instalação é formado pela junção do projetor, projeção e imagem projetada, e adiciona elementos como oscilação de velocidades e figuras mais complexas. Essas figuras são ondas e elipses que se movimentam, sugerindo uma interação entre elas. Seus movimentos são principalmente verticais, mas há também uma movimentação horizontal resultante das projeções que cruzam as formas, que se cobrem e descobrem alternadamente. Algumas mudanças em relação aos primeiros filmes de luz sólida, feitos em película de $16 \mathrm{~mm}$, podem ser observadas. Neste caso específico, as figuras, bem como as velocidades em que se movem, são variadas, criando uma tensão maior ao seu redor. Tal como seu título sugere, Meeting You Halfway acontece no "meio do caminho" entre as figuras, as figuras e os véus de luz, a imagem e o movimento, o tempo e o espaço, o elementos físicos da instalação e o espectador. 

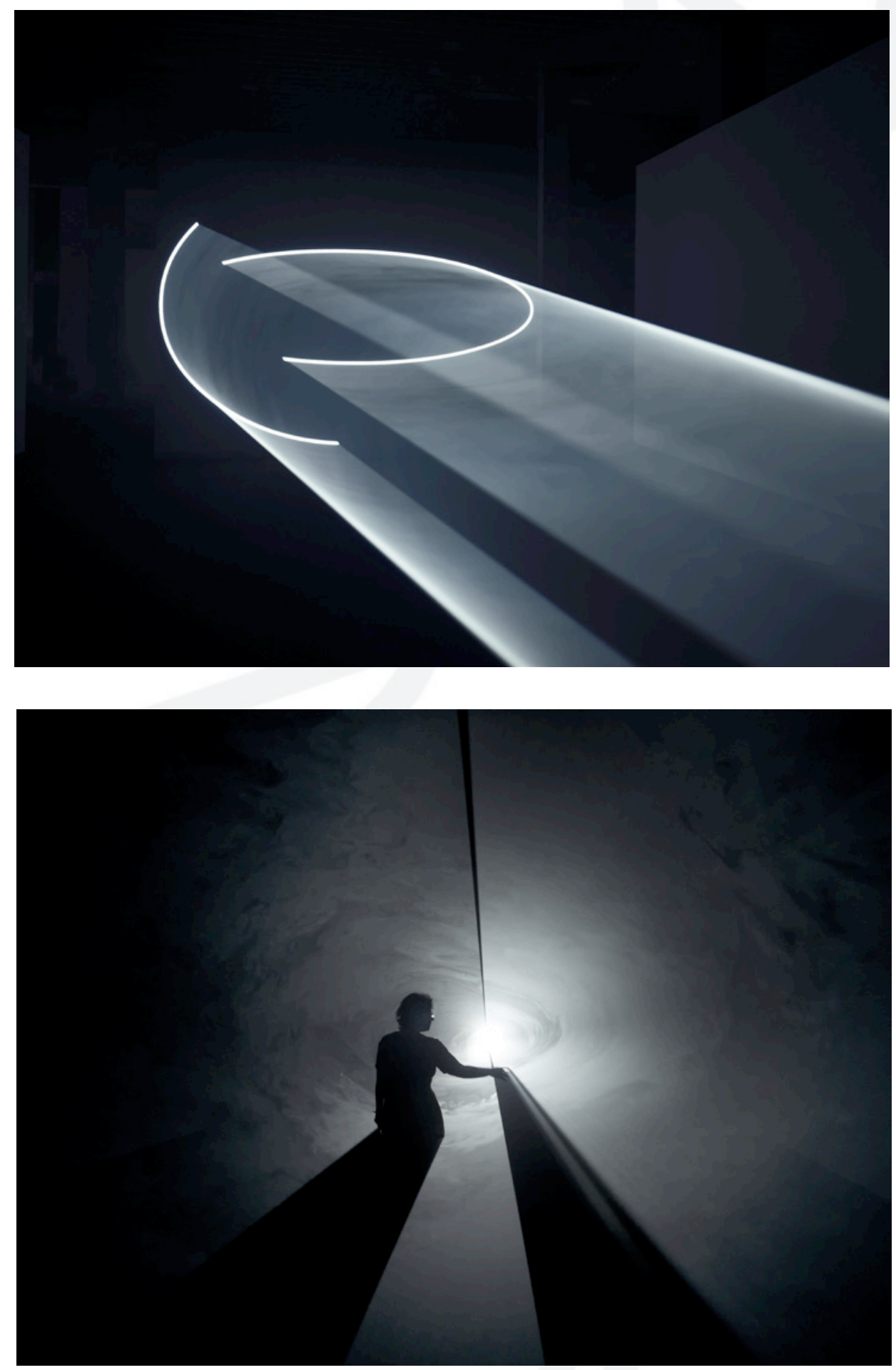

Figura 2. Anthony McCall. Meeting You Halfway (2009). Visão da instalação; LAC, Lugano; 2015. Fotografia de Anna Domenigoni.

Fonte: Anthony McCall. 
Uma proposta similar pode ser notada em Between You and I (2006) (Figura 3 e Figura 4). Realizada três anos antes de Meeting You Halfway, essa obra já sugeria a observação dos interstícios. A principal diferença em relação à instalação de 2009 e à maioria dos filmes de luz sólida é a orientação dos véus. Esse caso é marcado por uma configuração mais inusitada, na qual os projetores são colocados acima do espectador, e as figuras são projetadas no chão. Esses elementos instigam uma participação mais ativa no descobrimento da estrutura subjacente à obra. Como não há nenhuma sugestão antevista no título quanto à metamorfose das figuras, o visitante deve estar atento às suas formas para desvendá-la. As figuras desveladas são uma elipse, que se contrai e se expande, uma onda, que vagueia em relação à elipse, e uma linha, que atravessa e confunde as demais formas ao rodar. Essa interação entre tais componentes ocorre em velocidade reduzida, possibilitando a observação de suas relações.

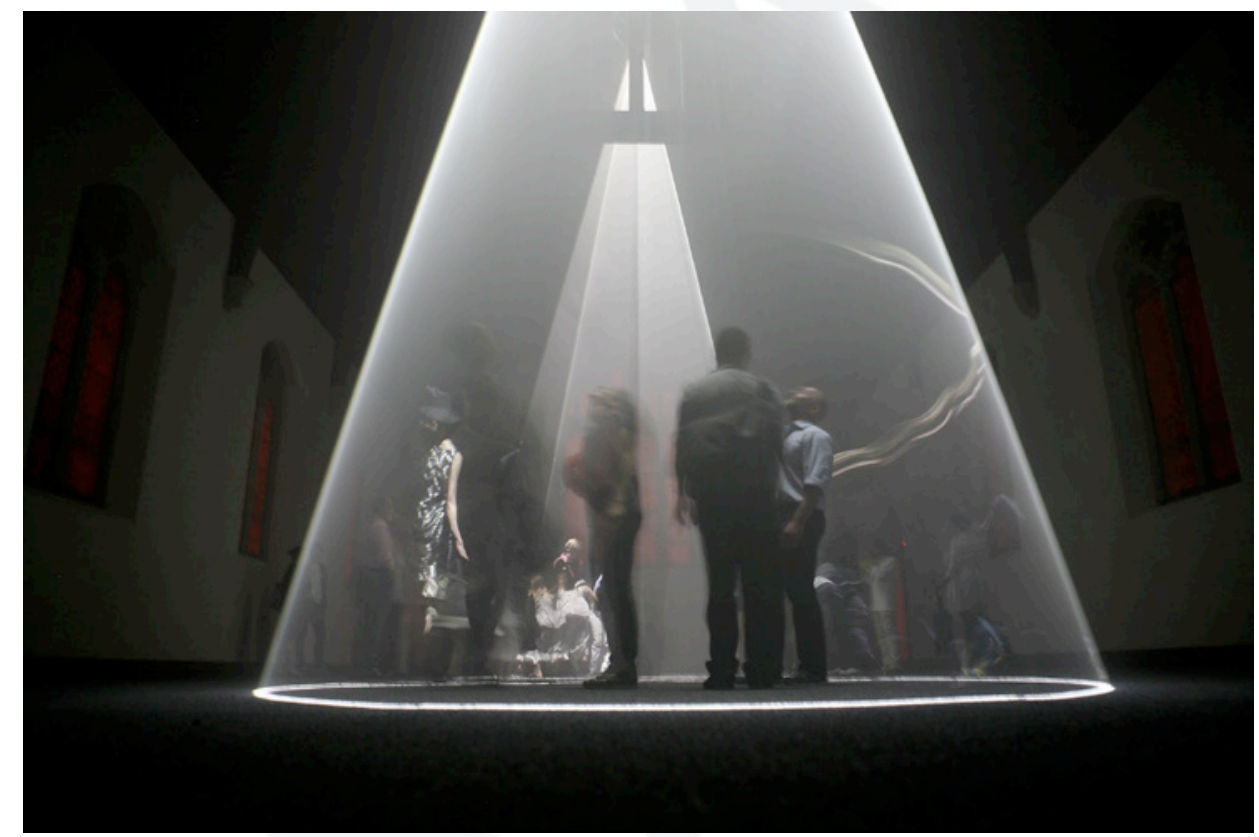

Figura 3. Anthony McCall. Between You and I (2006). Visão da instalação 'Plotog', St. Cornelius Chapel, Governor's Island, 2009. Fotografia de Sam Horine. Cortesia Creative Time.

Fonte: Anthony McCall. 


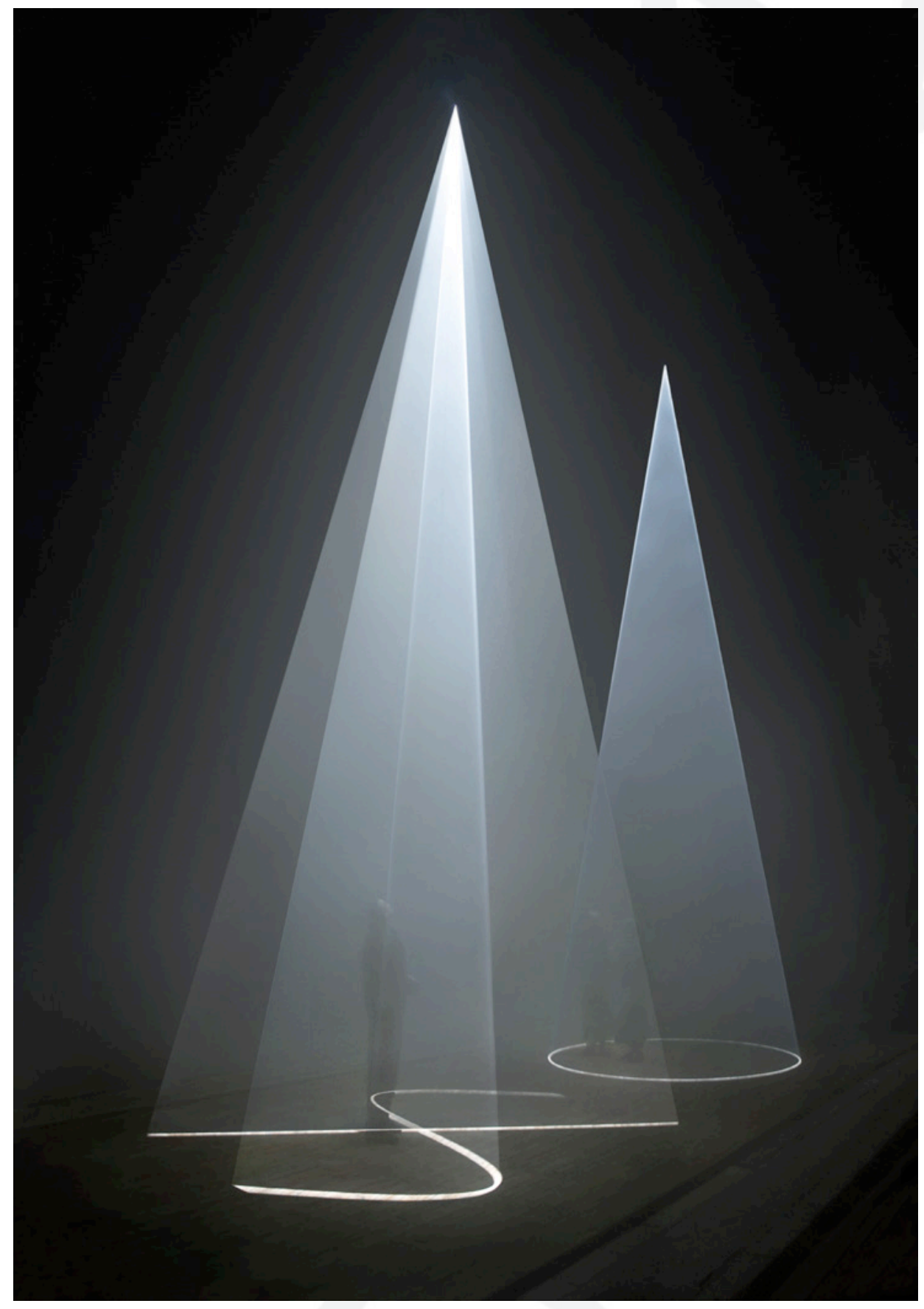

Figura 4. Anthony McCall. Between You and I (2006). Visão da instalação no Peer/The Round Chapel, Londres, 2006. Fotografia de Hugo Glendinning.

Fonte: Anthony McCall.

Ambos esses filmes de luz sólida mantêm alguns princípios, tais como o lento movimento das figuras projetadas, o jogo com a corporeidade das luzes e do 
espectador, e a possibilidade de uma fruição individual que também se abre para o envolvimento entre espectadores na experiência da instalação.

Esses aspectos compõem os principais critérios utilizados por Hal Foster em $O$ Complexo arte-arquitetura (2011) para qualificar as obras de McCall em oposição ao espetáculo ${ }^{3}$. Para ele, o jogo com efeitos de luz geralmente implica um aumento da ilusão, tendência que não se aplicaria aos filmes de luz sólida, já que eles envolvem, em suas palavras, "um espectador em movimento, que também esteja perceptiva e cognitivamente alerta, [e que] faz contraponto ao sujeito deslumbrado ou imobilizado de um espetáculo privado ou ao menos não social" (FOSTER, 2015, p. 214). Essa fala caracteriza um estado de deslumbramento, que implica a inibição da consciência pelo excesso de estímulos sensórios, em oposição a um estado de atenção alerta. Os filmes de McCall ofereceriam um contraponto a esse estado, mas será que suas obras seriam totalmente destituídas de todo efeito visual ilusório?

Para investigar essa questão, gostaria de rememorar alguns aspectos elencados por Walter Benjamin em relação às mudanças na percepção oriundas da emergência da imagem técnica. Seria pretensioso retomar esse autor para tentar extrair de seus textos algo que já não tenha sido amplamente abordado por inúmeros e competentes estudiosos de sua obra. ${ }^{4}$ O objetivo aqui é modesto. Proponho uma interpretação da obra de McCall a partir de algumas noções e temas benjaminianos, atualizados por Hal Foster e Oliver Grau, com o objetivo de repensar seu caráter ilusório.

\footnotetext{
${ }^{3}$ Conferir, especialmente, os capítulos O cinema desnudado, p. 197-214, e A liberação da pintura, p. 215-246.

${ }^{4}$ Conferir, por exemplo, Comentários sobre Benjamin e A obra de arte, de Detlev Schöttker, Estética e anestética: uma reconsideração de A obra de arte da Walter Benjamin, de Susan BuckMorss; e Benjamin, cinema e experiência: a flor azul na terra da tecnologia, de Mirian Hansen. Todos esses textos foram publicados, juntamente a uma tradução de $A$ obra de arte na era de sua reprodutibilidade técnica, em: BENJAMIN, Walter; SCHÖTTKER, Detlev; BUCK-MORSS, Susan; HANSEN, Mirian. Benjamin e a obra de arte: técnica, imagem, percepção. Organização de Tadeu Capistrano. Tradução de Marijane Lisboa e Vera Ribeiro. Rio de Janeiro: Contraponto, 2012.
} 


\section{RECEPÇÃO ÓPTICA E RECEPÇÃO TÁTIL}

Logo no início de seu ensaio $A$ obra de arte na era de sua reprodutibilidade técnica (1935), Benjamin (1994, p. 166) declara que os conceitos que irá abordar devem ser úteis para reivindicações revolucionárias na arte. Isso significa que ele se coloca a serviço de uma resistência política à tendência ao fascismo e à proletarização das massas. 0 autor considera que mais importante do que questionar se a fotografia ou o cinema são arte é questionar se, por meio da invenção desses meios, o caráter geral da arte foi modificado. É nesse sentido que propõe algumas diferenciações entre a obra de arte reprodutível e a obra de arte "tradicional", ou seja, sua busca se relaciona especialmente com as mudanças perceptivas oriundas da emergência das imagens técnicas.

Benjamin considera duas formas de recepção (ou fruição) relativas a esses paradigmas da obra de arte. A recepção óptica liga-se à contemplação e ao recolhimento, típicos da aura, enquanto que a recepção tátil refere-se à distração e ao hábito. A recepção tátil, característica da reprodutibilidade e do cinema, teria sido iniciada com os dadaístas e se tornado proeminente na arquitetura. Em outras palavras, as estratégias dadaístas de choque físico e moral teriam preconizado a recepção tátil, mas é na arquitetura que Benjamin encontra o modelo de uma recepção coletiva e dispersa, tal como configurada no cinema.

Longe de sistematizar esses modos de fruição para separá-los em polos incomunicáveis, Benjamin sugere que a arte pode abarcá-los em oposição à tendência dominante (ao fascismo). Segundo o autor, "através da distração, como ela nos é oferecida pela arte, podemos avaliar, indiretamente, até que ponto nossa percepção está apta a responder a novas tarefas" (BENJAMIN, 1994, p. 194). Assim, se a estetização da política convergiria para a guerra, a politização da arte poderia efetuar um equilíbrio entre natureza e homem por meio da mediação técnica. $\mathrm{O}$ tipo de mediação demarcaria a diferença entre uma tendência e outra. 


\section{SUBLIME E TECNOLÓGICO}

É a partir dessas considerações benjaminianas que Hal Foster faz referência à questão da mediação em sua crítica ao sublime tecnológico, atrelado ao espetáculo. Esse é um ponto importante de sua argumentação, na qual associa a alta mediação tecnológica à alienação do espectador. Por estar apartado dos métodos de produção, que resultam em estímulos sensórios de grande impacto na sua percepção, o espectador seria iludido e alienado por sensações que não Ihe pertenceriam.

Resumidamente, a diferença entre o sentimento do sublime kantiano e o sublime tecnológico consiste nas operações que os geram e nos efeitos que suscitam. Originalmente, o sublime decorre, por exemplo, da dificuldade de apreendermos a grandeza das forças naturais. Por sua vez, como podemos supor a partir do termo, o sublime tecnológico resulta de construções altamente mediadas pela racionalidade técnico-científica. Foster observa que o sublime tecnológico é "minuciosamente construído, amiúde com o apoio de intensas intervenções de capital, tecnologia e trabalho que servem para estetizar o natural e naturalizar o estético" (FOSTER, 2015, p. 242). Em seu processo de elaboração, a maior parte dessas intervenções é camuflada, dando a impressão de que o fenômeno produzido é imediato a nós, ou seja, ocorre sem mediações. Para ele, o segundo momento desse tecnossublime estético evoca "o sentimento oceânico" descrito por Freud como um "narcisismo ilimitado disfarçado de uma perda do Eu, em que o Eu comunga com sua própria euforia, confundindo-a com a grandeza da arte" (FOSTER, 2015$, p. 242$)^{5}$. O campo da psicanálise é convocado para sustentar sua tese de que o sublime tecnológico ocasionado por determinadas obras estaria associado ao processo de reificação do homem operado pelo capitalismo, devido à sua manufatura e recepção. O segundo momento do sublime kantiano, no qual haveria o resgate da capacidade humana de apreensão dos

\footnotetext{
${ }^{5}$ A referência usada por Foster é: FREUD, Sigmund. O mal estar da civilização. Tradução de Paulo César de Souza. São Paulo: Penguin Classics Companhia das Letras, 2011.
} 
fenômenos, seria substituído por um sentimento de grandeza resultante de uma combinação de narcisismo e alienação, ainda segundo Foster.

Para chegar a essa conclusão, ele se reporta aos comentários de Benjamin acerca dos graus de ilusão de determinados modos de produção de obras de arte. Por exemplo, no teatro, como os atores atuam diante do público, a ilusão produzida seria de primeiro grau. No cinema, devido à inserção do aparelho de captação e montagem entre atores e público, a ilusão produzida seria de segundo grau. A diferença entre ambos está no modo como determinada realidade ficcional é construída. Nos termos de Benjamin,

no estúdio o aparelho impregna tão profundamente o real que o que aparece como realidade 'pura', sem o corpo estranho da máquina, é de fato o resultado de um procedimento puramente técnico, isto é, a imagem é filmada por uma câmera disposta num ângulo especial $e$ montada com outras da mesma espécie. (BENJAMIN, 1994, p. 186 , grifo do autor)

Deste modo, complementa, "a realidade, aparentemente depurada de qualquer intervenção técnica, acaba se revelando artificial, e a visão da realidade imediata não é mais que a visão de uma flor azul no jardim da técnica" (BENJAMIN, 1994, p. 186). Benjamin sugere que a realidade aparentemente pura apresentada pelo cinema é resultado de uma intensa mediação técnica, em grande medida ignorada pelos espectadores. Em vista disso, Foster utiliza justamente essa passagem para compor sua noção do sublime tecnológico. ${ }^{6} \mathrm{Em}$ nenhum momento, porém, os comentários benjaminianos sugerem que esse grau de ilusão operado pelo cinema deveria ser lido em chave negativa, tal como realiza Foster ao avaliar a mediação técnico-racional e os intensos estímulos sensórios como elementos necessariamente alienantes.

\footnotetext{
${ }^{6}$ Sua leitura de Benjamin é devedora, em grande medida, da interpretação realizada por Miriam Hansen em Benjamin, cinema e experiência: a flor azul na terra da tecnologia.
} 
Com isso, parece importante diferenciar dois tipos de ilusão tratados no ensaio de Benjamin. O primeiro relaciona-se à ilusão de participação criada pela indústria cinematográfica, por exemplo, no destaque dado aos atores e demais produtos gerados ao seu redor, esse sim de caráter massificante e alienante. ${ }^{7}$ O segundo refere-se aos modos de construção de obras de arte, que resultam em ficções nas quais sua manufatura nem sempre é evidente. Nesse sentido, se o cinema produz essencialmente uma ilusão de segundo grau, caberia ao artista romper essa ilusão e expor as diretrizes de seu programa para o espectador. Outra linha de interpretação poderia sugerir a criação de tensão entre os graus de ilusão.

Esta linha parece se aproximar mais do pensamento benjaminiano, ao passo que Benjamin reconhece uma dimensão de resistência à estetização da política no próprio cinema. Essa dimensão residiria no modo como o mundo é representado pelas lentes, que possibilitaria o conhecimento do inconsciente óptico. De acordo com essa leitura, a câmera operaria de modo análogo à psicanálise, no sentido de possibilitar uma ampliação da percepção corriqueira e até mesmo sublimar certas tendências. ${ }^{8}$ Já em Pequena história da fotografia (1931), Benjamin esboçava essa ideia quando afirmava que

a natureza que fala à câmera não é a mesma que fala ao olhar; é outra, especialmente porque substitui a um espaço trabalhado conscientemente pelo homem, um espaço que ele percorre inconscientemente. Percebemos, em geral, o movimento de um homem que caminha, ainda que em grandes traços, mas nada percebemos de sua atitude na exata fração de segundo em que ele dá um

\footnotetext{
${ }^{7}$ Cf. BENJAMIN, 1994, p. 184-185.

8 "Se levarmos em conta as perigosas tensões que a tecnização, com todas as suas consequências, engendrou as massas - tensões em que estágios críticos assumem um caráter psicótico -, perceberemos que essa mesma tecnização abriu a possibilidade de uma imunização contra tais psicoses de massa através de certos filmes, capazes de impedir, pelo desenvolvimento artificial de fantasias sadomasoquistas, seu amadurecimento natural e perigoso. A hilaridade coletiva representa a eclosão precoce e saudável dessa psicose de massa. A enorme quantidade de episódios grotescos atualmente consumidos no cinema constituem um índice impressionante dos perigos que ameaçam a humanidade, resultantes das repressões que a civilização traz consigo. Os filmes grotescos, dos Estados Unidos, e os filmes de Disney, produzem uma explosão terapêutica do inconsciente. Seu precursor foi o excêntrico. Nos novos espaços de liberdade abertos pelo filme, ele foi o primeiro a sentir-se em casa. É aqui que se situa Chaplin, como figura histórica." (BENJAMIN, 1994, p. 190)
} 
passo. A fotografia nos mostra essa atitude, através dos seus recursos auxiliares: câmera lenta, ampliação. Só a fotografia revela esse inconsciente ótico, como só a psicanálise revela o inconsciente pulsional. Características estruturais, tecidos celulares, com os quais operam a técnica e a medicina, tudo isso tem mais afinidades originais com a câmera que a paisagem impregnada de estados afetivos, ou o retrato que exprime a alma do seu modelo. (BENJAMIN, 1994, p. 94-95, grifo nosso)

Os intermédios da câmera poderiam, portanto, ampliar a percepção dos espectadores, no sentido de revelar nuances e detalhes não percebidos corriqueiramente. Residiria aí a diferença entre uma tendência massificadora e alienante e uma forma de resistência a essa inclinação, que instigaria o pensamento do espectador.

\section{MODALIDADES DE ILUSÃO}

Em uma elaboração similar a Benjamin, mas contemporânea, Oliver Grau (2007, p. 291) ressalta que a montagem de uma interface em realidade virtual sempre resulta de uma escolha política, e que a atuação dos artistas pode auxiliar no desenvolvimento de um novo papel para os espaços virtuais, "como ampliadores da experiência no mundo físico". Esse autor faz referência direta ao filósofo alemão e realiza uma espécie de atualização de seu pensamento sobre o cinema, ao considerar a questão da ilusão vinculada com as realidades virtuais.

Em Arte virtual: da ilusão à imersão (2003), Grau faz uma análise das tendências poéticas oriundas das tecnologias digitais, com foco em obras que exploram elementos de ilusão, imersão e transmissão em tempo real. 0 autor realiza essa análise considerando um contexto mais amplo na história da arte, em pinturas de períodos anteriores que já demonstravam uma tendência à ilusão e à imersão desde a Antiguidade. Sua proposta se baseia na compreensão de que o aspecto ilusório faz parte do modo como humanos se relacionam com imagens, portanto a questão da imersão não iniciaria com as realidades virtuais, ainda que essas 
sejam essencialmente imersivas. ${ }^{9}$ Seguindo essa linha de pensamento, Grau (2007, p. 27) pondera que a "crise de representação" diagnosticada e teorizada por Baudrillard desde os anos 1970 "não difere qualitativamente das condições de representação encontradas em mídias mais antigas de imagens", ou seja, as tecnologias mudam, mas há questões concernentes à imagem que se mantêm, tais como a ilusão e a imersão.

Em síntese, o autor define os termos ilusão e imersão do seguinte modo. A ilusão relaciona-se aos efeitos não herméticos de meios como a pintura trompe l'oeil, na qual a mídia é facilmente reconhecível, e às imagens ou aos espaços imagéticos que são delimitados por uma estrutura aparente ao observador, tais como o teatro ou a televisão. Grau sistematiza duas funções da ilusão. A primeira refere-se ao prazer estético, resultante de seu aspecto "lúdico" e de uma "submissão consciente à aparência". A segunda relaciona-se ao poder sugestivo da imagem, isto é, à inibição temporária da percepção de diferença entre realidade e espaço imagético, por meio da intensificação dos seus efeitos. Para o autor, essa função visa a "enganar os sentidos e leva o observador a agir ou a se sentir de acordo com a cena ou a lógica das imagens e, até certo ponto, ao fascínio da consciência" (GRAU, 2007, p. 35-36). Haveria, portanto, uma ilusão "consciente" e uma ilusão "inconsciente". Essa serviria de ponte para a constituição da imersão. Diferentemente da ilusão (com sua estrutura aparente), a imersão vincula-se às imagens em 360 graus, que circundam o espectador, constituídas em mídias distintas, tais como salas de afrescos, panoramas, cinema circular e CAVES. ${ }^{10} \mathrm{~A}$ principal diferença entre

\footnotetext{
${ }^{9}$ Segundo Grau, "a expressão 'realidade virtual', que é em termos um paradoxo, descreve um espaço de possibilidade ou impossibilidade formado por estímulos ilusórios dirigidos aos sentidos. Em contraste com a simulação, que não precisa ser imersiva e refere-se essencialmente ao factual ou ao possível sob as leis da natureza, a estratégia de realidade virtual de imersão formula o que 'é dado em essência', um 'faz-de-conta' plausível, que pode instaurar espaços utópicos e fantásticos. Realidades virtuais - tanto atuais como antigas - são, em essência, imersivas." (GRAU, 2007, p. 32-33)

${ }^{10}$ Grau usa a seguinte definição de Cruz-Neira et al: "A CAVE (Cave Automatic Virtual Environment) é um cubo em que todas as seis superfícies podem ser usadas como telas de projeção, circundando o(s) visitante(s) com um ambiente de imagens. Usando óculos obturadores de cristal líquido, os shutterglasses, óculos estereoscópicos leves, os usuários veem as imagens em 3D." (GRAU, 2007, p. 16)
} 
ambas consiste no fato de que a ilusão deixa o observador fora da imagem, enquanto que a imersão possibilita ao espectador adentrá-la. Dentro da imagem, o poder de sugestão ilusória da imagem é intensificado.

Especificamente, nas realidades virtuais, a imersão opera de modo multissensorial. Tal como observa Grau (2007, p. 32), o objetivo é "fornecer ao espectador a impressão mais intensa possível de estar no local onde as imagens estão, o que requer a mais exata adaptação da informação ilusória para a disposição fisiológica dos sentidos humanos". Para alcançar esse objetivo, as interfaces devem ser, nos termos usados pelo autor, "naturais", "intuitivas" e "fisicamente íntimas". As realidades virtuais tendem, portanto, a maximizar a ilusão. Grau (2007, p. 30) avalia que a imersão é "sempre caracterizada pela diminuição da distância crítica do que é exibido e o crescente envolvimento emocional com aquilo que está acontecendo". Nesse sentido, os espaços virtuais imersivos oferecem uma realidade completamente alternativa, possibilitando mudanças radicais dos parâmetros de tempo e espaço, permitindo, assim, experimentos associados à telepresença e às realidades mistas. $\mathrm{O}$ autor reconhece que

quando está realmente imerso em um espaço de alta resolução, de ilusão de 360 graus, somente com grande dificuldade o observador consegue manter alguma distância da obra ou objetivá-la. [...] $\mathrm{Na}$ melhor das hipóteses, o meio realidade virtual pode ser objetivado pelo conhecimento e crítica dos métodos de produção de imagem e pela compreensão de seus mecanismos técnicos, fisiológicos e psicológicos, pois tudo é imagem. (GRAU, 2007, p. 231-232)

Justamente essa transformação de tudo em imagem potencializa o choque promovido pelo cinema, tal como concebido por Benjamin. É como se os efeitos descritos por esse filósofo passassem por um processo de renovação com meios mais sofisticados, no qual são intensificados. Nos termos de Grau, "quanto mais 'naturais' se tornam as interfaces, maior o perigo - não somente de a maior parte do 'iceberg tecnológico' ficar inacessível ao usuário não ciente dele - de ocorrer um desaparecimento ilusório dos limites ao espaço de dados" (GRAU, 2007, p. 233). Ainda, assim como Benjamin, Grau também reconhece que as 
mídias imagéticas tendem a avançar para servir a interesses que pretendem manter o poder ou a maximização dos lucros. Em suas palavras,

\begin{abstract}
ao longo da história, os poderes dominantes tendem a pressionar a mídia mais avançada para estar a seu serviço, usando-a para a autoglorificação e, de acordo com as circunstâncias, para denegrir ou incriminar seus oponentes. Esse processo tomou a forma de gigantescas imagens de propaganda, carregadas em desfiles triunfais pelas cidades no início da era moderna, ou, mais tarde, das imagens nos panoramas, no cinema e na internet. Um aspecto aparente do conceito de imersão é ela engajar-se na concentração espacial e pictórica da consciência de um povo, na formação da identidade coletiva através de imagens poderosas, que ocupam a função de memória. [...] O ganho com o poder de sugestão é, assim, revelado como um objetivo primário e uma motivação central no desenvolvimento de novas mídias de ilusão. Essa parece ser a motivação principal de seus criadores, os quais, constando com um potencial sugestivo maior, intensificam o poder sobre os observadores, a fim de erigir o novo regime de percepção. (GRAU, 2007, p. 398)
\end{abstract}

Através dessas considerações, é possível notar que Grau desenvolve sua tese acerca das realidades virtuais tendo em vista o histórico de ilusão na arte e no cinema, vinculado a sua dimensão política. Seu comentário acerca da correlação entre as imagens e seu poder de sugestão com repercussão política remete à fortuna crítica iniciada com Benjamin e Adorno ${ }^{11}$. Esses autores tratam, sobretudo, da instauração de regimes da percepção que atrelam as imagens à manutenção do poder. Uma característica constante, portanto, das pinturas em panorama às realidades virtuais, seria o princípio de imersão, ou seja, de "ocultar a aparência do meio ilusório verdadeiro, mantendo-o abaixo do limiar perceptivo do observador, para maximizar a intensidade das mensagens que estão sendo transmitidas" (GRAU, 2007, p. 394). A invisibilidade do meio auxiliaria, portanto, as instâncias de poder dominantes.

Novamente de modo similar a Benjamin, Grau avalia a possibilidade de abalo dessas instâncias. Por exemplo, revelar parcialmente a estrutura subjacente à

\footnotetext{
${ }^{11}$ Conferir, por exemplo, as considerações adornianas sobre a indústria cultural em: ADORNO, Theodor W. A indústria cultural. (1967) Theodor Adorno: sociologia. Organização de Gabriel Cohn. Coordenação de Florestan Fernandes. São Paulo: Ática, 1986, p. 92-99.
} 
obra resguardaria certa possibilidade de distanciamento crítico. Essas considerações parecem se alinhar à avaliação de Foster acerca do sublime tecnológico, já que ressaltam a importância do esclarecimento dos mecanismos que geram a ilusão em obras de arte contemporâneas mediadas pelo pensamento técnico-racional.

Mas será que apenas ao mostrar as estruturas subjacentes a determinado sistema as obras de arte poderiam exercer um papel subversivo aos sistemas de poder? Grau auxilia na resposta dessa questão ao considerar que "a aparência das imagens raramente revela alguma informação sobre o código em que se baseia". Assim, acrescenta que, "apesar de as convenções de armazenamento determinarem com precisão o tipo a que pertence determinado arquivo, uma quantidade de dados incrivelmente diferente pode existir sem afetar de forma alguma a aparência da imagem" (GRAU, 2007, p. 294). Se considerarmos que a maior parte das obras não revela sua manufatura, sobretudo quando produzidas com tecnologias digitais mais recentes, é preciso verificar se não haveria outro caminho possível para a realização de obras engajadas a contrapelo da tendência que "neutraliza" a percepção. Grau observa que

recentes descobertas da neurobiologia propõe que aquilo que chamamos de realidade é de fato apenas uma afirmação sobre o que podemos realmente observar. Qualquer observação depende dos nossos limites mentais e físicos individuais e de nossas observações teóricas e científicas. Somente dentro dessa estrutura somos capazes de fazer as observações que nosso sistema cognitivo, dependendo desses limites, permite-nos observar. (GRAU, 2007, p. 36-37)

Nesse sentido, caberia ao artista auxiliar o espectador na ampliação de seu olhar ou de sua percepção e, consequentemente, de sua capacidade cognitiva, usualmente tão enfraquecida pela ordem do espetáculo. Essa função poderia ser realizada com o uso de imagens técnicas e seus aparelhos, dado que eles podem funcionar como máquinas de tradução de impressões sensórias e ferramentas de pensamento. 
Grau examina que a relação particular entre artista e computador seria responsável por produzir "concepções" por meio de diálogos com os sistemas em busca de "possíveis" atualizações. ${ }^{12} \mathrm{E}$ afirma que "o artista agora opera no campo de força entre o domínio da ferramenta utilizada e a emancipação do poder normativo da ferramenta, isto é, sua domesticação" (GRAU, 2007, p. 302). Por um lado, os aparelhos suscitam o domínio de suas ferramentas, isto é, de sua usabilidade por parte do artista. Por outro, o artista os "domesticam" apenas quando se emancipa de seu uso, ou seja, somente quando joga contra a sua finalidade originária. $\mathrm{O}$ autor ressalta que

numa obra de arte virtual, além do fator da interação, é a interface, especialmente a interface natural, que representa o domínio central da criação artística, que pode ser implementada com fins emancipatórios ou manipulativos, ambas as opções tão intimamente interligadas que chegam a ser quase inseparáveis. Considerando o potencial sugestivo dos espaços imagéticos virtuais, a questão do desenho da interface, a conexão de dados ao corpo, adquire importância fundamental. (GRAU, 2007, p. 302)

A partir do reconhecimento do papel central que a interface exerce, o que passa a estar em jogo são os afetos evocados pelas superfícies e os modos como os artistas despertam a consciência e mobilizam o inconsciente do espectador. Essa ideia reafirma as possibilidades já aventadas por Benjamin em relação ao cinema. Desde então, as imagens já podiam ser usadas para fins diversos, cabendo ao artista se inserir nesse campo de disputa para introduzir incertezas e incitar uma ampliação da percepção óptica e tátil nos espectadores.

Tendo isso em vista, afirma Grau remetendo ao comentário de Susan Sontag acerca do mito da caverna de Platão ${ }^{13}$, "a questão não é sair da caverna, pois

\footnotetext{
${ }^{12}$ Essa ideia parece ecoar as considerações de Vilém Flusser quanto à noção de caixa-preta, que se refere diretamente ao complexo formado pela relação entre aparelho e operador. Nesse complexo, o operador estaria sempre em busca de resultados "improváveis" no funcionamento corriqueiro dos aparelhos. Conferir: FLUSSER, Vilém. Filosofia da caixa preta: ensaios para uma futura filosofia da fotografia. (1983) São Paulo: Annablume, 2011.

${ }^{13}$ Logo no início de Sobre fotografia: ensaios (1977), Sontag escreve: "A humanidade permanece, de forma impenitente, na caverna de Platão, ainda se regozijando, segundo seu costume ancestral, com meras imagens da verdade. [...] Essa insaciabilidade do olho que
} 
não há como sair da história das mídias". E acrescenta: "Há somente mídias velhas e novas, tentativas velhas e novas de criar ilusões: é imperativo o engajamento crítico em sua história e em seu desenvolvimento futuro" (GRAU, 2007, p. 402).

Em síntese, as ideias de Grau e Benjamin se aproximam da proposta de Foster em relação à importância de manter marcas da manufatura nas obras realizadas com alta mediação tecnológica. Ao mesmo tempo, porém, a avaliação desses autores sugere a possibilidade de usar novas tecnologias da imagem em favor de processos políticos emancipatórios sem que essa ação seja necessária. Mais importante do que deixar as marcas de realização seria, portanto, colaborar com a ampliação da percepção dos espectadores através de diferentes interfaces.

\section{POÉTICA DA PRESENÇA NOS FILMES DE LUZ SÓLIDA}

Considerando a reconstrução de alguns dos principais argumentos de Benjamin, Grau e Foster acerca dos modos de fruição de imagens a partir do advento do cinema, é possível responder à questão colocada inicialmente acerca dos filmes de McCall, a saber: será que sua obra é totalmente destituída de qualquer caráter ilusório?

Como foi abordado anteriormente, o primeiro filme de luz sólida, Line Describing a Cone apresenta uma figura abstrata muito simples, um círculo, que se formava lentamente na tela de cinema. A partir do momento em que essa obra foi configurada como instalação, a atenção geralmente dada às imagens passou a ser dividida com o projetor e, sobretudo, com a projeção, que adquiriu uma corporeidade quase tão sólida quanto a do espectador. Essa qualidade fez com que um modo de fruição inédito se formasse. Mesmo não

\footnotetext{
fotografa altera as condições do confinamento na caverna: o nosso mundo. Ao nos ensinar um novo código visual, as fotos modificam e ampliam nossas ideias sobre o que vale a pena olhar e sobre o que temos o direito de observar. Constituem uma gramática e, mais importante ainda, uma ética do ver." (SONTAG, 2004, p. 13)
} 
sendo possível modificar os véus de luz, o espectador busca tocá-los. Essa intenção se deve ao fascínio que produzem. Deste modo, ao mesmo tempo em que o espectador passa a estar ciente dos elementos materiais que compõem o cinema, encanta-se com essa figura formada pela luz no espaço. As luzes possibilitam a imersão ao mesmo tempo em que a visibilidade do projetor funciona como um lembrete da estrutura que sustenta a obra.

Por sua vez, Meeting you Halfway e Between you and I parecem sintetizar alguns elementos presentes nos filmes de luz sólida. Essas duas instalações mantêm em tensão diversos aspectos, tais como uma recepção multissensorial resultante da combinação entre linguagens artísticas e o jogo de aproximações e distinções entre arte e espetáculo. Especialmente, indicam a constituição de um interstício, isto é, um espaço intermediário, que se forma especialmente na instalação, entre seus aspectos materiais e imateriais e o espectador. É como se ambos constituíssem, juntos, uma presença única que envolve todos os demais encontros mencionados, por exemplo, entre imagem, projetor e projeção; entre linguagens artísticas; entre visão e tato; entre recepção óptica e tátil. Essa presença reúne aspectos conscientes e inconscientes. É por isto que a obra de McCall sugere o ultrapassamento dos pressupostos do sublime tecnológico, tal como conceituado por Foster: não apenas porque resistem à alienação vinculada ao espetáculo, mas porque demandam que o espectador se coloque em estado de presença ao mesmo tempo atenta e distraída, nos termos benjaminianos.

A obra de McCall parece desenvolver o potencial observado pelos autores comentados em relação à politização da arte. A combinação dos diferentes modos de fruição permite, além disso, que suas instalações sejam também cognitivas. O espectador é levado para um estado de atenção atípico, no qual se conscientiza das formas, dos volumes, do espaço, da presença dos demais espectadores e de si próprio, ao observar vagarosamente as mudanças que suas ações acarretam nos véus de luz, sombras e figuras. Sua obra gera um estado de presença, que poderia sugerir a principal diferença entre sua poética e os espetáculos de efeitos sensórios que apartam o espectador de si. É como 
se suas imagens de tempo restituíssem o corpo a uma presença individual e compartilhada, não para uma exploração desmedida e hedônica do presente, mas para um cuidado de si, do outro e do mundo, efetuando um movimento contrário à alienação do espetáculo.

\section{REFERÊNCIAS}

\section{Bibliografia citada}

ADORNO, Theodor W. A indústria cultural. (1967) Theodor Adorno: sociologia. Organização de Gabriel Cohn. Coordenação de Florestan Fernandes. São Paulo: Ática, 1986, p. 92-99.

ALMEIDA, Fernanda A. de. Imagens de tempo nas poéticas tecnológicas de Harun Farocki, Bill Viola e Anthony McCall. 2019, 189 f. Tese (Doutorado em Estética e História da Arte) - Universidade de São Paulo. São Paulo, 2019. Disponível em:

<https://www.teses.usp.br/teses/disponiveis/93/93131/tde-16102019154240/pt-br.php >. Acesso em 16 abr. 2020.

BAUDRILLARD, Jean. Simulacros e simulação. (1981) Tradução de Maria João da Costa Pereira. Lisboa: Relógio d'água, 1991.

BENJAMIN, Walter. A obra de arte na era de sua reprodutibilidade técnica. (1935) In: Magia e técnica, arte e política. Ensaios sobre literatura e história da cultura. Obras escolhidas, volume 1. Tradução de Sergio Paulo Rouanet. São Paulo: Brasiliense, 1994.

Pequena história da fotografia. (1931) Magia e técnica, arte e política. Ensaios sobre literatura e história da cultura. Obras escolhidas, volume 1. Tradução de Sergio Paulo Rouanet. São Paulo: Brasiliense, 1994.

BENJAMIN, Walter; SCHÖTTKER, Detlev; BUCK-MORSS, Susan; HANSEN, Mirian. Benjamin e a obra de arte: técnica, imagem, percepção. Organização de Tadeu Capistrano. Tradução de Marijane Lisboa e Vera Ribeiro. Rio de Janeiro: Contraponto, 2012.

BRITO, Luciana (Galeria). Anthony McCall. São Paulo: Luciana Brito Galeria, 2011.

CRUZ-NEIRA, C. et al. Surround-screen Projection-based Virtual Reality: the Design and Implementation of the Cave. In: ACM SIGGRAPH'93, Computer Graphics Proceedings. New York: ACM SIGGRAPH Papers, 1993, p. 135-142. 
FLUSSER, Vilém. Filosofia da caixa preta: ensaios para uma futura filosofia da fotografia. (1983) São Paulo: Annablume, 2011.

FOSTER, Hal. O complexo arte-arquitetura. (2011) Tradução de Célia Euvaldo. São Paulo: Cosac Naify, 2015.

FREUD, Sigmund. O mal estar da civilização. Tradução de Paulo César de Souza. São Paulo: Penguin Classics Companhia das Letras, 2011.

GRAU, Oliver. Arte virtual: da ilusão à imersão. (2003) Tradução de Cristina Pescador, Flávia Gisele Saretta e Jussânia Costamilan. São Paulo: Editora UNESP: Editora Senac São Paulo, 2007.

HOBBS, Robert. Anthony McCall's Cybernetic Systems. Anthony McCall: Solid Light, Performance and Public Works. Barcelona: Ediciones Polígrafa, 2017.

KANT, Immanuel. Crítica da faculdade do juízo. Tradução de Valerio Rohden e Antônio Marques. Rio de Janeiro: Forense, 1993.

McCALL, Anthony. Line Describing a Cone and Related Films. In: October, v. 103. The MIT Press, 2003.

PLATÃO. A república. Tradução de Carlos Alberto Nunes. Belém: Edufpa, 2017.

SONTAG, Susan. Sobre fotografia: ensaios. (1977) Tradução de Rubens Figueiredo. São Paulo: Companhia das Letras, 2004.

\section{LISTA DE FIGURAS}

Figura 1: Anthony McCall, Line Describing a Cone (1973), durante o vigésimo quarto minuto. Visão da instalação no Musee de Rochechouart (2007). Fotografia de Freddy Le Saux. Cortesia Sean Kelly Gallery, Nova York, Galerie Thomas Zander, Colônia, Galerie Martine Aboucaya, Paris. - pág.: 14

Figura 2: Anthony McCall. Meeting You Halfway (2009). Visão da instalação; LAC, Lugano; 2015. Fotografia de Anna Domenigoni - pág.: 16

Figura 3: Anthony McCall. Between You and I (2006). Visão da instalação 'Plot09', St. Cornelius Chapel, Governor's Island, 2009. Fotografia de Sam Horine. Cortesia Creative Time - pág.: 17

Figura 4: Anthony McCall. Between You and I (2006). Visão da instalação no Peer/The Round Chapel, Londres, 2006. Fotografia de Hugo Glendinning - pág.: 18 


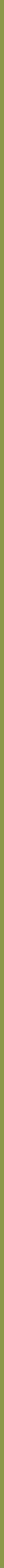

